International Journal of Engineering \& Technology, $7(3.12)(2018) 84-88$
International Journal of Engineering \& Technology
SPC
Website: www.sciencepubco.com/index.php/IJET
Research paper

\title{
Controlling of PV-STATCOM for Increasing Power Transmission based on VHDL Signal Generation
}

\author{
B.Pragathi ${ }^{1}$, M.Suman ${ }^{2}$ \\ ${ }^{1}$ Research Scholar, Dept. of ECE, Koneru Lakshmaiah Education Foundation, Vaddeswaram, \\ Guntur, A.P, India \\ ${ }^{2}$ Associate Professor, Dept. of ECE, Koneru Lakshmaiah Education Foundation, Vaddeswaram, \\ Guntur, A.P, India \\ Corresponding Author E-mail: ${ }^{1}$ pragathibellamkonda@gmail.com, ${ }^{2}$ suman.maloji@ kluniversity.in
}

\begin{abstract}
Along with Generation of power, distribution of power is equally important.The power produced by the solar farm are utilized only during daytime, the solar farm remain idle during night and operate below capacity in initial morning and late afternoon. A grid connected solar farm uses photovoltaic (PV) arrays for generation of DC power which is transformed to AC using inverter modeling. A FACTS family device STATCOM is centered on a voltage source converter which operates as a rectifier and an inverter is used to enhance steady power transmission limits with reactive power, voltage and damping control. A majorsection of the STATCOM is a voltage source converter which is also anessential element of PV solar module. A novel concept was proposed by which PV solar module can be operated as a STATCOM, known as PV-STATCOM in the night-time and day time. VLSI technology is used to generate the trigger pulses for three phase inverter using the VHDL programming language to generate the signal for the control of inverter section in STATCOM. The HDL compiling and FPGA implementation is done using MATLAB/SIMULINK.
\end{abstract}

Keywords: Photovoltaic (PV) Solar module, inverter section, PV-STATCOM, Power Compensation, Voltage Control, Damping Control, PWM, VHDL

\section{Introduction}

Production of power is a typical task now days, as many energy sources are present to produce power. Due to the increased pollution, cost and scarcity of available resources, everyone is focusing on the eco-friendly renewable resources for generation of power. Out of the existing renewable resources, solar energy is the important one, generating electric energy from light energy. Solar cells are used to convert photon energy into electrical energy. Many kinds of solar cells are available in according to our requirement [1].Increasing the solar efficiency is a critical task, the final voltage of solar cells be determined bythe module arrangement, number of diodes used in a single PV- cell [2].The output power from the PV cell depends on many factors such as electrical characteristics and irradiances from sun, when the PV cell is represented in its electrical equivalent circuit [3].Since the PV output is built on the radiation from the sun, PV cells measurements are taken under different testing conditions of radiation [4]. The DC power from PV module are not constant throughout the day, by using MPPT algorithms we can tract the maximum power produced by the PV modules. Different algorithms are specified using mathematicalequations, to acquire accuracy [5].Along with mat lab Simulink; one can acquire the exact results using matlab coding for different direct methods of MPPT algorithms [6]. Perturb and observe method is a direct method of MPPT algorithm for tracking maximum output power from PV modules by comparing the present power values with recent values and incrementing/decrementing the corresponding voltages [7]. The generated DC power must travel a long way to reach the grid. Transmission losses are overcome by means of STATCOM [8].It is used as ac-dc/dc-ac converter. The main section of STATCOM is VSC, and controlling of VSC is done through many techniques [9].Controlling of Voltage regulation, reduction of harmonics and increasing the efficiency is carried out using PV-STATCOM [10].PWM method is used for controlling the gating pulses of switches in the VSC section [11].HDL coding is used for generating the PWM signal for controlling of the inverter section [12].

\section{Methods and Methodology}

Block diagram shown in figure. 1 consist of PV panel which generates the DC power. Buck converter is used for DC-DC conversion. To maintain the concentrated power from PV panel and generation of duty cycle for buck converter is maintained by using perturb and observe MPPT algorithm. STATCOM is used for DC-AC conversion, the VSC section is controlled through FPGA.VHDL coding is used for pulse generation for firing the igbt in the vsc section. 


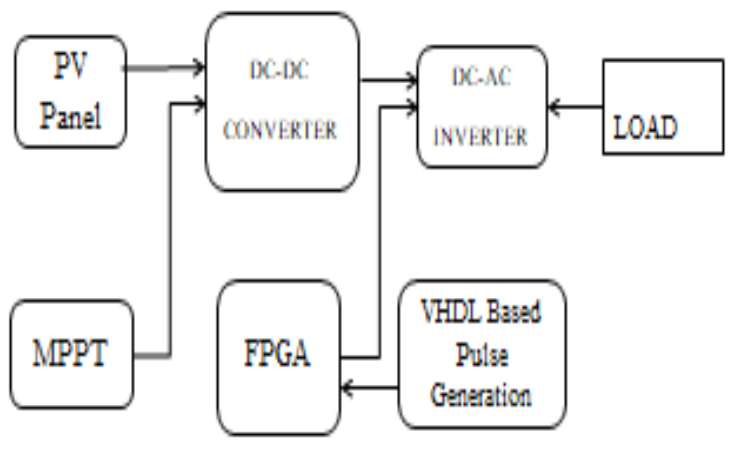

Fig. 1: Methodology

\section{Photovoltaic (PV) Cell}

The PV cell depends on the photovoltaic effect, which generates DC power when light is incidence on the cell. The light energy is converted to electrical energy. The PV cell construction is similar to PNjunction; with P-type and N-type semiconductor joining together. When external biasing is applied a depletion region is from near the junction because of the diffusion of electrons of $\mathrm{N}$ type material and holes of P-type material. When light is incidence on this PN junction the photon energy creates the charge carriers which are separated from the junction. These charge carriers may be electron-ion pair or electron-hole combination in semiconductor material, which creates potential gradients at the junction. The electric field is produced in the junction and current runs through the external circuit. The power generated by the PV cell is calculated under standard test condition (STC).It is measured in watts. The PV cells are arranged in series -parallel combination to form the PV modules. The efficiency of the PV module based on the space occupied by the PV module. Several PV modules joined together forms a PV module. The power formed by the PV cell based on the irradiance and temperature of the sun. The equivalent circuit for PV panel is shown in figure.2.

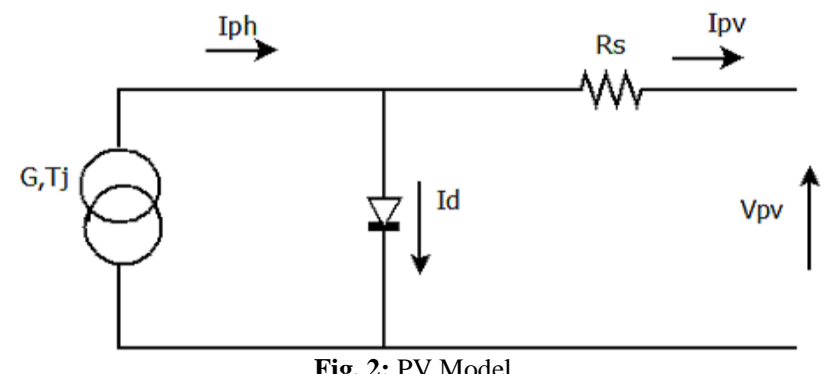

\section{Maximum Power Point Tracking (MPPT)}

Since the power generated by the PV module depends on the sun irradiance and temperature throughout the day, power of PV array is varied throughout the day. So tracking of the maximum power causedby the PV module is asignificant task. Different controller methods are used for controlling the maximum power point of the system known as maximum power point tracking (MPPT).The point on the output curve where maximum power is produce is called as point of locus. Many algorithms have come around to determine the maximum power of PV array. The algorithms are divided as direct method and indirect method.

Indirect method MPPT algorithms: constant voltage method, fixed variable voltage method.

Direct method of MPPT algorithms: perturb and observe method, hill climbing method, incremental conductance method, Fuzzy logic and artificial neural network.

\section{Perturb and Observe Method}

Perturbation and observe method shown in figure 4, also known as Perturb and observe method, most precisely used MPPT algorithm. It is a "trial \& error" method. The output power is detected by The PV controller increases the inverter reference output power by the PV controller. The references voltage is increased until the output voltage is gradually increased and then decreased; the controller also decreases its references voltage, to avoid nonlinear features of PV controller. The flow chart of P\&O method is shown below. Initial values of voltage $V(k)$ and Current I (k) Power P (k) = V (k)*I (k) is compared with the previous value of power given as $\mathrm{P}(\mathrm{k}-1)$.Is compared with the previous power $\mathrm{P}(\mathrm{k}-1)$. If the power is increased, it retains the next voltage in same direction. Else, change the voltage in the opposed direction.

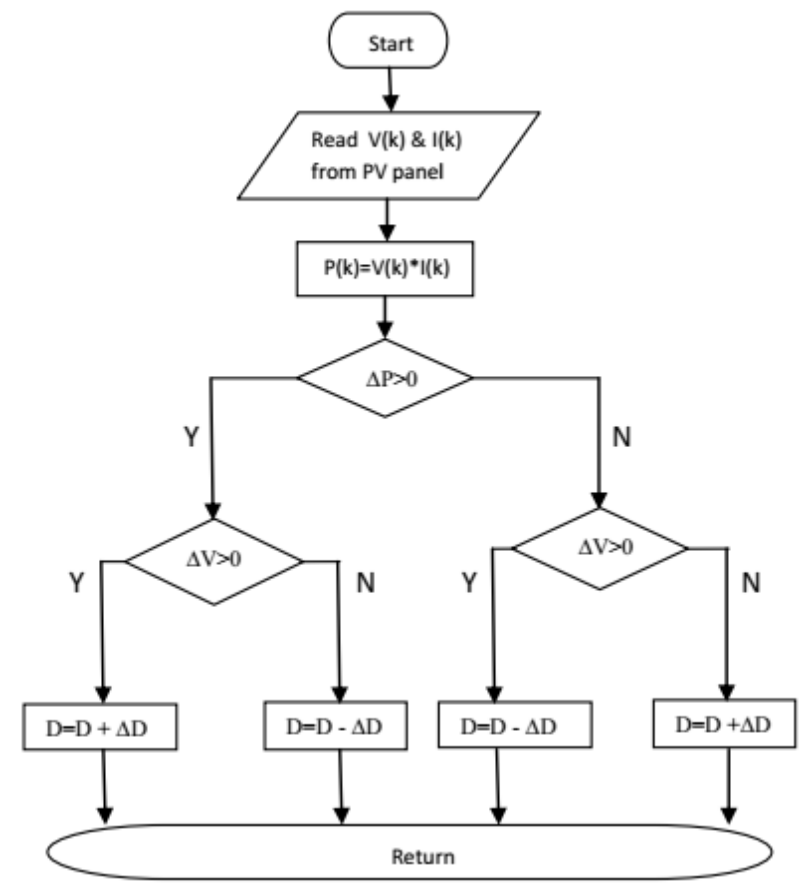

Fig. 4: $\mathrm{P} \& \mathrm{O}$ algorithm

\section{DC-DC Converter}

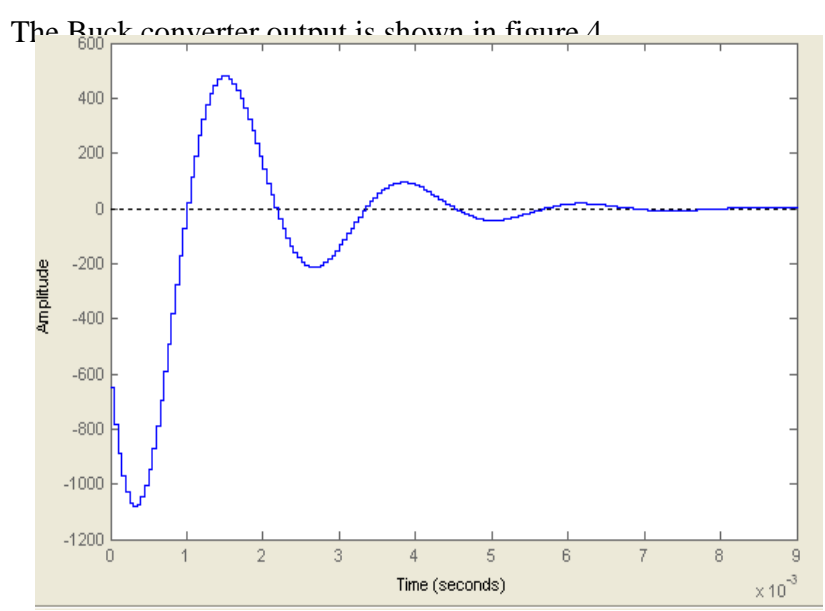

Fig. 4: Buck converter output

Buck converter is used for DC-DC conversion of the PV output power. The duty cycle is adjusted using MPPT algorithm.

\section{STATCOM}

STATCOM is a FACTS family shunt connected device adept of producing real and reactive power, capable of compensating reactive power and controlling certain parameters of the power array. The input of the STATCOM is linked from the external DC 
energy storage device. STATCOM has a voltage source converter, which acts as the inverter, performing DC to three phase AC conversion. The three in-phase voltages of VSC are connected to external grid through interface reactance's and even generates or absorbs the power at the mutual coupling point.

\section{Improving factors of the power system}

1. STATCOM Controls the dynamic voltage in distribution and transmission systems.

2. Improves power oscillation damping in the systems

3. Increases the transient stability

4. Controlling the voltage flickering in system

5. Controlling of active and reactive power

\section{Solar PV Farm Operated as Conventional PV STATCOM}

The figure below shows how a PV system is utilized as a conventional STATCOM which provides voltage regulation, reactive power requirements, etc.The STATCOM system has a capacitor, VSC. The DC voltage from the capacitor is given to the VSC section, where the DC is converted to AC.This generated AC power is used to Drive the grid.

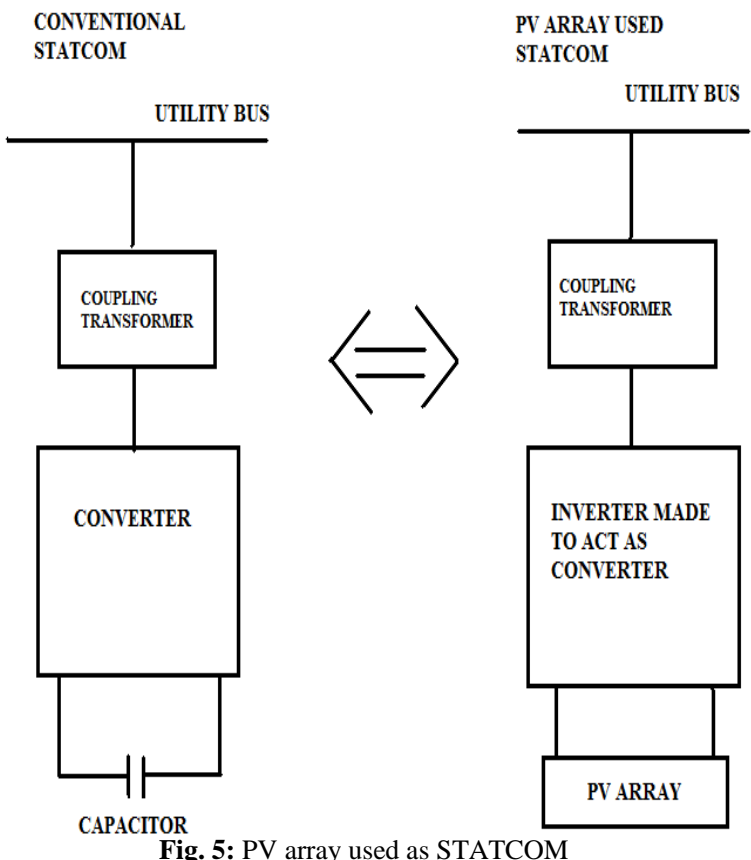

In PV based system, the DC voltage from the PV array is used to drive the inverter section. The controlling of the IGBT switches is done using PWM signal generation, which is produced using VHDL coding, which reduces the harmonic distortion present in the output.

In the PV-STATCOM based system, during day time the DC power generated from the PV system is used to drive the VSC and during night the battery supplies the required power to drive the VSC section. In PV-STATCOM instead of using the capacitor power, the DC power from the PV array is used and PV array is used as capacitor. The VSC section is replaced by the inverter section, which is used to drive the external grid.

\section{PV-STATCOM Operation Modes}

The PV-STATCOM is operated in three different modes (1) day time mode of process, (2) excess power mode of process, (3) night time mode of process.

1. Day time mode of process: In this mode of process, When the output voltage of PV is as per the requirement of the buck-boost inverter input, without charging the battery the PV system is directly connected to the converter to match the three leg VSC dc link by boosting up the voltage.

2. Excess power mode of process: In this mode of operation, The PV system output voltage drives the buck-boost converter based PV-STATCOM for the source compensation and charging the battery.

3. Night time mode of process: In this mode of operation, Due to the absence of PV power, the input for the buck-boost converter is provided by the battery by providing night time compensation.

\section{Generation of PWM Signal}

It is to be noted that the control of the output AC voltage is been done through PWM signal which offers following advantages over the traditional methods:

1. Reduction of harmonics and voltage is controlled using PWM.

2. RFI and EMI effects are reduced by the software generated PWM pulses.

3. The system weight and cost.

This PWM signal is used for triggering the inverter section, where a HDL code is written using VHDL and it is been simulated using MATLAB and is dumped into a FPGA chip implemented in SIMULINK. 6 output pins of the FPGA chip give the required 6 PWM pulses. Behavioral modelling style is used for writing VHDL code. The VHDL coding for PWM pulse generation is presented as flowchart in figure.6.

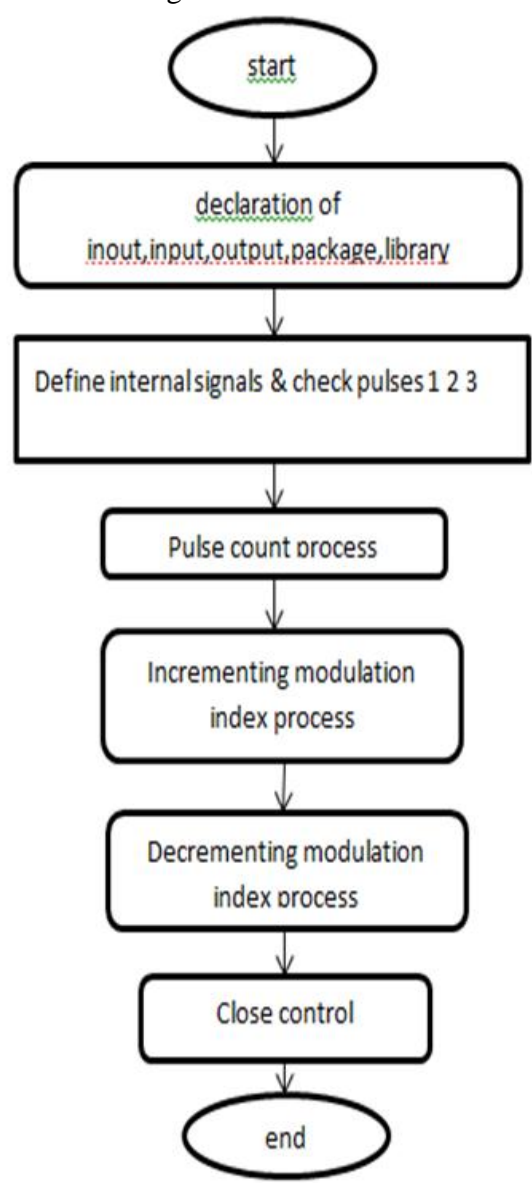

Fig. 6: PWM flowchart

\section{Results}

The simulation is done using MATLAB/SIMULINK. The PWM signal is produced using VHDL coding, which is applied to three phase inverter. The output power is measured by regulating the modulation index from 0001 to 1010.Figure.7, Figure.8 and Figure. 9 shows the PV cell maximum output voltage, using MPPT 
algorithm. Mat lab coding is used to produce the required PV output.Figure. 4 shows the buck-boost converter output, where the output DC voltage amplitude is increased.Figure.10 and Figure.11 shows the STATCOM/Inverter DC-AC conversion output.Figure. 12 shows the PWM signal generation using VHDL.

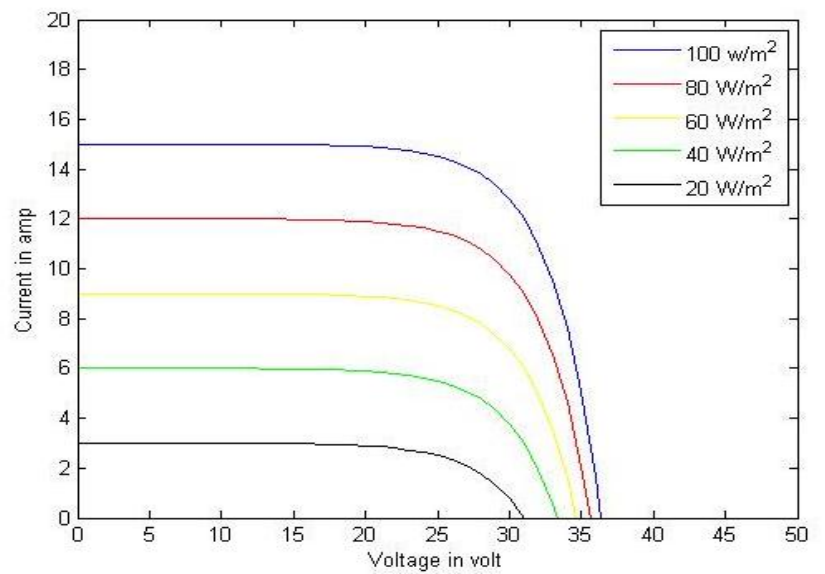

Fig. 7: PV cell output voltage Vs current

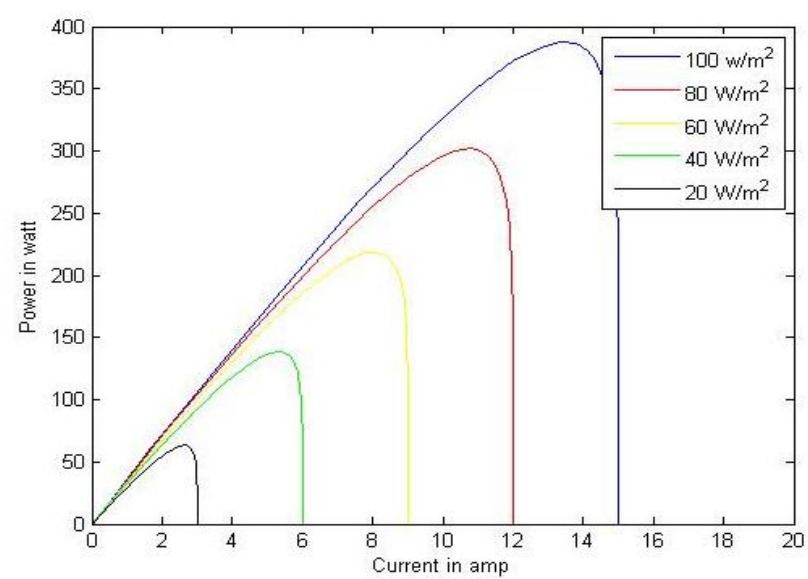

Fig. 8: PV cell output current Vs power

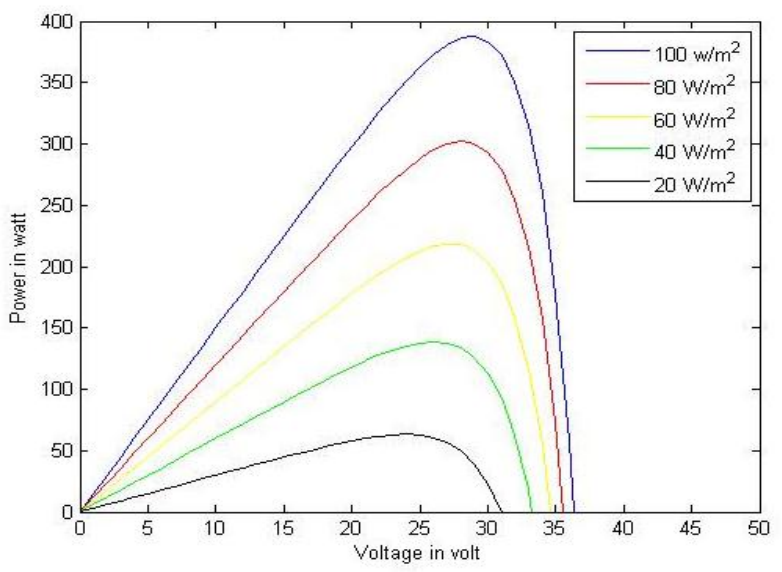

Fig. 9: PV cell output voltage Vs power

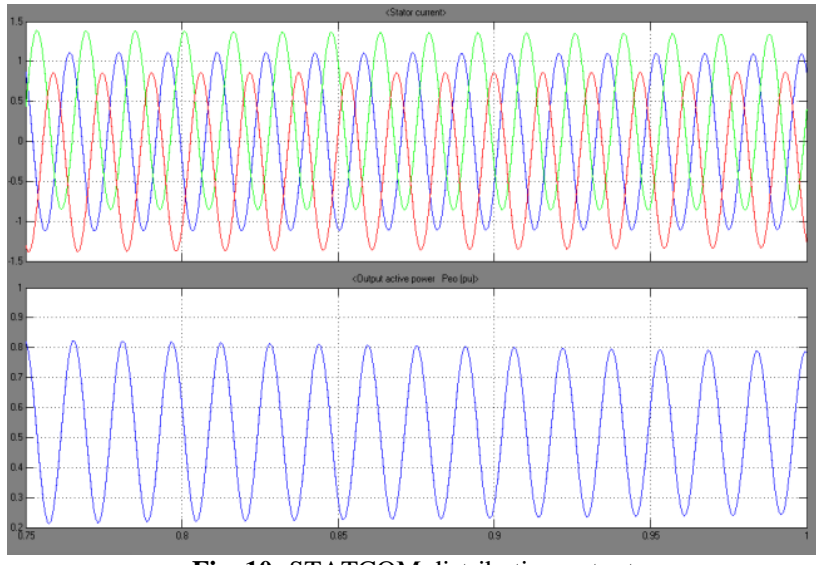

Fig. 10: STATCOM distribution output

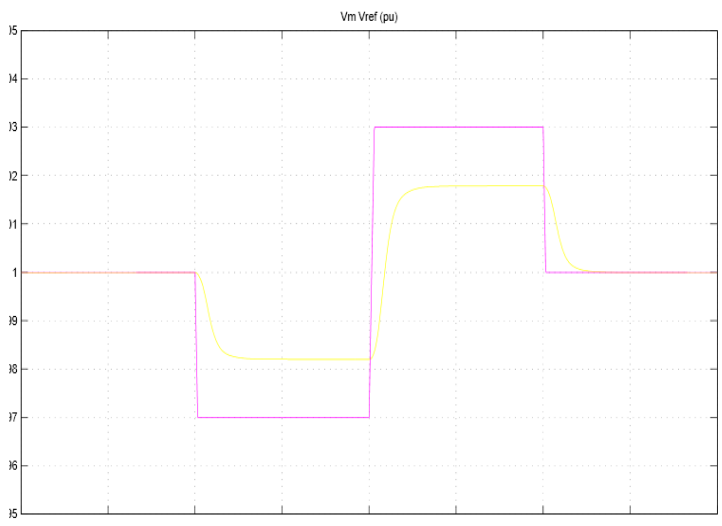

Gm Gret (pet)

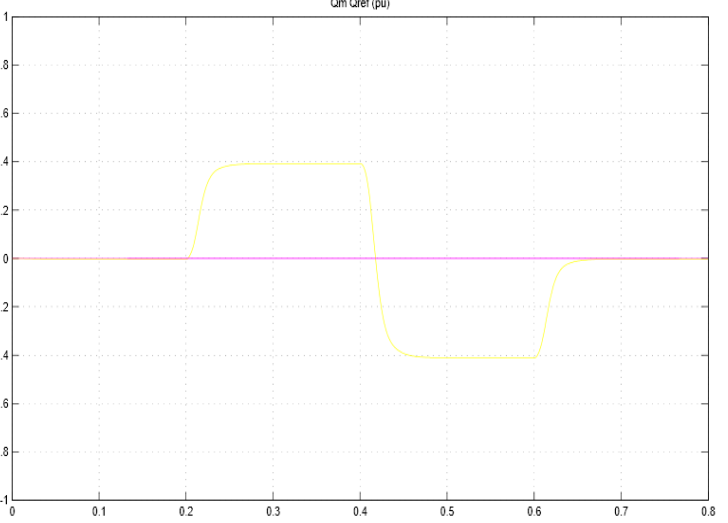

Fig. 11: STATCOM output

Edot Cursor zoom Format Wndow

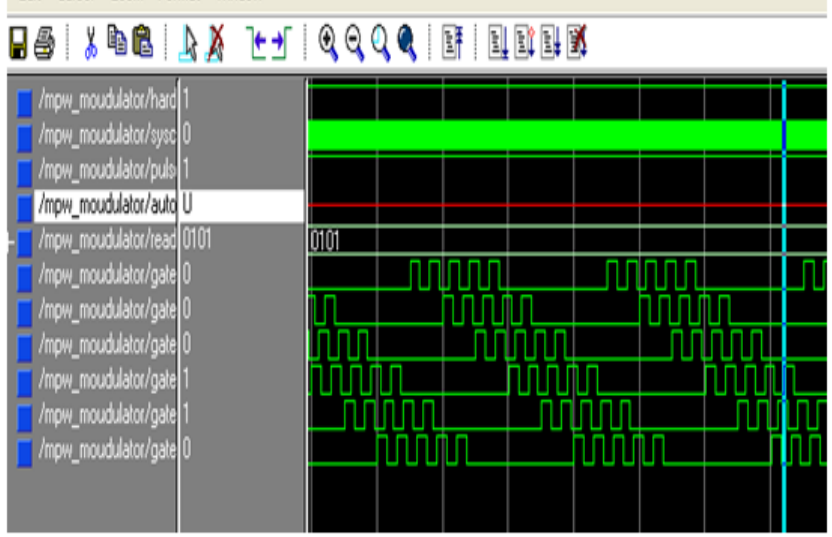

Fig. 12: PWM output for generation of control pulses for inverter section 
IGBT switches, thus reducing the harmonic distortion in output power. The simulation results show the section wise outputs for different input parameters.

\section{Conclusion}

A new concept of control mechanism is used in the PVSTATCOM.The PV system is used as STATCOM during nights, to improve the power transmission. Maximum power is generated from PV system using perturb and observe MPPT algorithm. A MATLAB/SIMULINK is used for modeling of PV array,MPPT and STATCOM.The main drawback of PV system being ideal during night time is overcome by this new technology of PVSTATCOM.The converter section of STATCOM is controlled using a new technique of utilizing HDL coding for controlling gating pulses of.

\section{References}

[1] Bagher, A.M., Vahid, M.M.A. and Mohsen, M., "Types of Solar Cells and Application. American Journal of Optics and Photonics," http://dx.doi.org/10.11648/j.ajop.20150305.17.

[2] T. Ahmad, S. Sobhan, M.F .Nayan,"Comparative analysis between single diode and double diode model of PV cell: Concentrate different parameters effect on its efficiency," J. Power Energy Eng. 4(03), 31 (2016).

[3] M. A. Hasan and S. K. Parida , "An overview of solar photovoltaic panel modelling based on analytical and experimental viewpoint," Renewable Sustainable Energy Rev. 60, 75-83 (2016).

[4] Lhoussain El Bahir, Touria Hassboun "Accurate Maximum Power Point Tracking Algorithm Based on a Photovoltaic Device Model," Research Article, International Journal of Photo energy Volume 2017 (2017).

[5] G. Apostolou, A. Reinders, and M. Verwaal , "Comparison of the indoor performance of 12 commercial PV products by a simple model," Energy Sci. Eng. 4(1), 69-85 (2016).

[6] Sundharajan Venkatesan, Manimaran Saravanan "Simulation and experimental validation of new MPPT algorithm with direct control method for PV application ",Journal of Renewable and Sustainable Energy 8, 043503 (2016).

[7] Rahul S Sharma, P.K.Katti, "Perturb \& observation MPPT algorithm for solar photovoltaic system,"2017 International Conference on Circuit, Power and Computing Technologies (ICCPCT).

[8] Abayomi A. Adebiyi , K. T. Akindeji "Investigating the effect of Static Synchronous Compensator (STATCOM) for voltage enhancement and transmission line losses mitigation," 2017 IEEE PES PowerAfrica.

[9] Omkar K. Shinde ; V R S V Bharath Pulavarthi "STATCOM converters and control,A review ,2017 International Conference on Data Management, Analytics and Innovation (ICDMAI).

[10] Joseph Anthony Prathap, T. S. Anandhi,"Digital Pulse Width Modulation Controlled DC-DC Buck Converter using VHDL Coding, "Journal of Analog and Digital Devices.

[11] Archana C Shettar, K M Sudarshan ,Syed Rehman, "FPGA design and implementation of digital PWM technique for DC-DC converters," 2016 IEEE International Conference on Recent Trends in Electronics, Information \& Communication Technology (RTEICT).

[12] Ms.Sharwari, H Chavan, "FPGA based pulse width modulation control for DC motors, " International journal in research in electronics. 